A. Tyagi ${ }^{1}$, I. Boxx ${ }^{2}$, S. Peluso ${ }^{1}$, and J.A. O'Connor ${ }^{1}$. "Statistics of Local FlameFlame Interactions in Flame Interaction Zones of Two V-Flames", AIAA Scitech 2019 Forum, (AIAA 2019-0446).

${ }^{1}$ The Pennsylvania State University, University Park, PA. USA.

${ }^{2}$ Institute of Combustion Technology, German Aerospace Center. Stuttgart.

The AIAA version of the paper is accessible at https://doi.org/10.2514/6.2019-0446

On the AIAA web page https://arc.aiaa.org/doi/abs/10.2514/6.2019-0446

the interested reader can find other material published by AIAA 


\title{
Statistics of Local Flame-Flame Interactions in Flame Interaction Zones of Two V-Flames
}

\author{
Ankit Tyagi, ${ }^{1}$ \\ The Pennsylvania State University, University Park, PA, USA \\ Isaac Boxx ${ }^{2}$ \\ German Aerospace Center (DLR), Stuttgart, Germany \\ Stephen Peluso ${ }^{3}$, and Jacqueline O'Connor ${ }^{4}$ \\ The Pennsylvania State University, University Park, PA, USA
}

\begin{abstract}
The flame structure and dynamics of interacting turbulent premixed flames are dependent on interactions between the flow fields and scalar fields of individual flames. Studies have shown that local flame-flame interactions introduce a variety of effects on flame structure and propagation by changing the statistics of flame curvature, displacement speed, flame area fluctuations, and stretch-rates. The topology of interaction events can vary significantly in the interaction zones of turbulent flames. These interactions can also result in the formation of unburned and burned gas pockets. Understanding the behavior of these interaction events is of important to capture the destruction of the flame surface to develop better sub-grid scale turbulent combustion models for enhancing the design and operation of modern combustion devices. The goal of this study is to characterize the behavior of two interacting V-flames and the local flame-flame interaction characteristics in their interaction zones. High-speed OHplanar laser-induced fluorescence (OH-PLIF) is implemented to obtain instantaneous flame front locations of rod-stabilized $V$-flames in a dual-burner experiment. A non-rigid image registration technique is applied to flame images to track the topological changes occurring in small time steps. In particular, results are presented for the dynamics of the interaction zones of these flames to illustrate that large-scale oscillations are important in the occurrence of small-scale flame-flame interactions. Lower arrival frequencies for flame-flame interactions are widely distributed along the streamwise direction, connecting the large-scale global behavior to the sub-grid level behavior of turbulent $\mathrm{V}$-flames.
\end{abstract}

\section{Nomenclature}

$\begin{array}{ll}\mathcal{A} & =\text { amplitude } \\ I_{b} & =\text { instantaneous binary image intensity } \\ I^{\prime} & =\text { instantaneous fluctuating binary image intensity } \\ \hat{I} & =\text { harmonically reconstructed intensity } \\ \mathcal{R}_{I n t} & =\text { rate of flame-flame interactions } \\ \mathcal{R}_{p} & =\text { rate of pocket formations } \\ R e_{L_{11}} & =\text { turbulent Reynolds number } \\ S & =\text { flame spacing } \\ S t & =\text { Strouhal number } \\ U & =\text { bulk flow velocity } \\ \bar{C} & =\text { time-averaged progress variable } \\ f_{a} & =\text { flame-flame interaction event arrival frequency }\end{array}$

\footnotetext{
${ }^{1}$ Graduate Student, Mechanical Engineering, AIAA Student Member

${ }^{2}$ Staff Scientist, Institute of Combustion Technology, AIAA Associate Fellow

${ }^{3}$ Assistant Research Professor, Mechanical Engineering

${ }^{4}$ Assistant Professor, Mechanical Engineering, AIAA Senior Member
} 


$\begin{array}{lll}l_{f} & =\text { flame thickness } \\ L_{11} & =\text { integral length-scale } \\ s_{L} & =\text { unstretched laminar flame speed } \\ u^{\prime} & =\text { root-mean-square of fluctuating velocity components at burner exit } \\ x & =\text { streamwise direction } \\ y & =\text { cross-stream direction } \\ z & =\text { spanwise direction } \\ \Delta t_{\text {int }} & =\text { flame-flame interaction event time delay } \\ \theta & =\text { phase angle } \\ \kappa & =\text { curvature } \\ \phi & =\text { equivalence ratio } \\ D N S & =\text { direct numerical simulation } \\ F O V & =\text { field of view } \\ L E S & =\text { large eddy simulation } \\ O H-P L I F & =\text { OH-planar laser induced fluorescence } \\ P S D & =\text { power spectral density }\end{array}$

\section{Introduction}

In turbulent premixed combustion, local turbulent burning velocities are dependent on the structure and wrinkling of flames, which are affected by various parameters including local turbulence levels, shear layer geometry, flame attachment locations, and flame-flame interactions [1]. The impact of these parameters is not universal - their effects on flame structure and wrinkling are different for different flame configurations. Several studies have experimentally investigated the impact of turbulence on flame structure and wrinkling [2-16] and have provided a foundational understanding of the behavior of flame structure and its impact on burning velocity and flame propagation. While these studies provide insightful information, the results obtained in these studies are limited to single-flame configurations. Present day combustion devices, such as jet engine combustors and augmentors, power generation gas turbines, and industrial boilers and furnaces, utilize multiple adjacent turbulent flames. In these devices, the interaction of individual flow fields and scalar fields from multiple flames changes the flame dynamics. Additionally, within the interaction zones of these flames, the flame wrinkling process is affected by changes in the local turbulence levels and flame structure.

Capturing the behavior of flame-flame interactions is a critical first step in the development of sub-grid models for some common large eddy simulations (LES). Many of these sub-grid scale turbulent combustion models use flame surface density (FSD) transport equations to model the flame behavior [17-23]. Appropriate prediction of flame surface generation and destruction is important to these models as the turbulent flame speed is known to directly correlate with FSD [4, 18]. Flame surface destruction is known to occur due to flame surface quenching and mutual flame-flame interactions in turbulent flames [18]. Several models have been proposed in the past to account for these destruction mechanisms [17, 19], although very few experimental studies have been performed that can be used to validate these models, including work done by Skiba et al. [24] and Worth and Dawson [25].

These flame-flame interaction dynamics are particularly important to capture in V-flames as V-flames have been shown to have significant wrinkling as a result of the mean shear generated by the separating boundary layer from the bluff body. Studies of turbulent V-flames by Kheirkhah and Gülder [8-10, 26] have shown that topology of the flame front significantly varies with changes in the inlet turbulence intensities. Formations of flame cusps are enhanced as the inlet turbulence levels increase to moderate levels. Additionally, freely propagating flames, flame pockets and localized extinctions are also reported to be observed in V-flames at high inlet turbulence levels [9]. In one of their studies, Kheirkhah and Gülder showed that flame front velocity statistics vary as a function of streamwise location from the flame holder location [26]. Their results showed that the transverse component of the reactants velocity in the vicinity of the flame front drives the fluctuation of the flame front and the flame front velocity. This mechanism also increases the flame front velocity as a function of downstream distance and at larger downstream distances, the flame front velocity is shown to be much greater than the corresponding laminar flame speed. These studies show that wrinkling is enhanced in V-flames at larger downstream distances and results in greater flame front propagation speeds.

Flame interaction zones have been a primary focus for a number of studies [27-33]; however, many of these studies have focused on flames undergoing thermoacoustic instability. Results from some of these studies have shown that flame area fluctuations from interactions between two adjacent flames can change the feedback mechanism and flame response [27-30]. Other studies have investigated the impact of interacting flames on global flame characteristics in 
gas turbine configurations; their results have shown that closer flame spacing results in a wide flame brush [31-35]. Worth and Dawson have also shown that greater levels of flame interactions result in increased negative curvatures; this increase in negative curvatures is due to enhanced flame cusping events in the interaction regions. Additionally, flame surface density fluctuations in acoustically forced flames increased at a greater rate than heat release rate fluctuations because of higher levels of mean flame stretch. More recent work by Worth and Dawson shows that a strong correlation exists between flame surface annihilation events and the fluctuation of the heat release rate in selfexcited oscillating, interacting V-flames [25]. Their results show that self-excited oscillations do not affect the probability of flame-flame interaction events but change their spatial distribution and phase, when compared with stable flames. Vortex dynamics in the merging region of adjacent flames are found to affect the location of flame channel closing events in the case of closely spaced interacting V-flames that result in phase changes in the heat release rates, impacting the stability of the system.

Direct numerical simulations (DNS) provide unique insights into the details of a flame-flame interaction event. DNS studies by Dunstan et al. [36, 37] investigated two interacting turbulent V-flames. In their study, local flameflame interactions were categorized into normal and counter-normal interactions. Normal interactions occur when flame surfaces propagate towards each other and reactants are consumed in the middle. Topologies of normal interactions can be categorized into: convex interactions, tunnel-closure interactions, and pocket burnout interactions. Convex interactions are quasi-one-dimensional, tunnel closure interactions are quasi-two-dimensional, and pocket burnout interactions are completely three-dimensional. Counter-normal interactions occur when the product-sides of the flame surfaces propagate towards each other and are quasi-one-dimensional in nature. Results from Dunstan's studies showed that a majority of normal interactions occurred in the flame interaction regions and counter-normal interactions occurred in the wakes of the bluff-bodies, where strong compressive strains were present. While this study used a single-step global chemical reaction, it was one of the only DNS to consider a V-flame configuration, where cylindrical flame holders were utilized that are more commonly used in laboratory-scale flames, resulting in a more realistic flow configuration.

Fundamental DNS studies have probed more deeply into the local structure of flames during the interaction events [38-47]. Using two-dimensional simulations, Chen et al. [39] have shown that local flame surface area, and consequently the heat release rate, changes significantly during a tunnel closure and subsequent pocket formation burnout. Their results show that the flame area decreases rapidly due to annihilation of the flame from the interaction event; global heat release trends follow the variation in flame area due to stretch effects. Results also show a four-fold increase in density-weighted displacement speed during pocket burnout, which occurs from preferential diffusion effects. Other simulation studies have also reported significant changes in flame propagation and consumption speeds during pocket burnout events [38, 45-47]. As highlighted by these results, flame surface destruction events directly affect the flame propagation speeds and heat release rates. Despite the high level of understanding gained from these DNS, the lack of large-scale computational domains and restricted flow configurations limit our understanding of these sub-grid scale level events for realistic combustion devices. For accurate modeling of the flame behavior at the sub-grid scale, it is important to obtain statistically converged experimental results to better predict the flame behavior and validate the sub-grid scale FSD models.

These previous studies show that interactions between flames both at large- and small-scales affect the flame behavior. Separately, these studies have provided insightful discussions on the effect of these interactions, however, only a few studies have investigated the transitive effects of large-scale interactions on small-scale interactions. The goal of this study is to preliminarily investigate the link between large-scale and small-scale interactions in the interaction zones of turbulent V-flames. In particular, the effect of interacting flames on the local flame morphology is characterized and compared for variations in absolute turbulence levels. High-speed flame front imaging is performed at three different flow conditions. A novel image processing technique is implemented and flame-flame interactions are statistically characterized to link the local behavior to large-scale motions observed along the flame front in these flames.

\section{Experimental Configuration and Diagnostics}

\section{A. Burner Configurations}

The experimental facility consists of two identical burners with $100 \mathrm{~mm}$ x $10 \mathrm{~mm}$ exit planes and $3.18 \mathrm{~mm}$ diameter circular bluff-bodies attached along the $100 \mathrm{~mm}$ length direction (Figure 1(a)). Each burner consists of two stacked sections that contain the inlet for the incoming flow, two layers of ceramic honeycombs and two perforated plates. A premixed natural gas and air mixture flows through the two layers of ceramic honeycomb inside the burners, which condition the flow before the mixture reaches the two perforated plates placed at $30 \mathrm{~mm}$ and $10 \mathrm{~mm}$ upstream of the burner exit. The perforated plates have a hole diameter of $3.18 \mathrm{~mm}$ and an open area of $40 \%$, resulting in the generation 
of averaged non-reacting flow turbulence-intensities of 18\%. More details of the burner are described in [48]. Each burner design also includes two types of pilot flames: small "anchoring" pilots, which are located close to the exit of the burners and help anchor the flames on the experiment, and larger "back-support" pilots, which provide adiabatic or super-adiabatic combustion products around the flames; however, pilot flames are not used in the current study. Instead, circular bluff-bodies are used as flame holders for the present study. These bluff-bodies block approximately $32 \%$ of the open area for reactant gas flow, leaving approximately $34 \%$ open area on either side of the bluff-bodies for each burner.

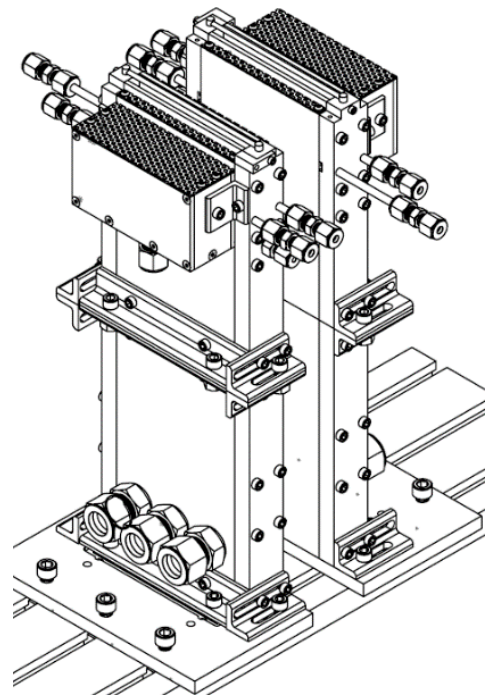

(a)

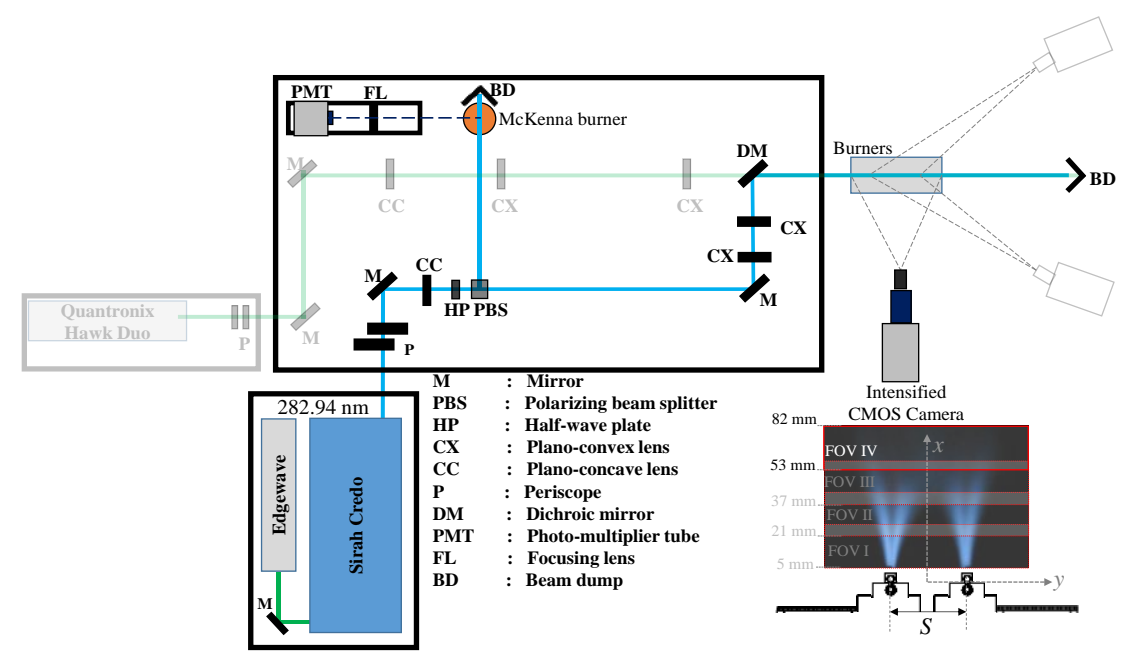

(b)

Figure 1: (a) Burner schematic and (b) optical diagnostics layout

\section{B. OH-Planar Laser Induced Fluorescence (OH-PLIF)}

A high-speed OH-PLIF system is used at $10 \mathrm{kHz}$ to obtain instantaneous flame fronts of flames investigated in this study (Figure 1(b)). The dye laser (Sirah Credo) of the system is tuned to the Q1(6) line of the $A^{2} \Sigma^{+} \leftarrow X^{2} \Pi$ (10 ) excitation band to excite the $\mathrm{OH}$ radicals with a wavelength of $282.94 \mathrm{~nm}$. The maximum pulse energy obtained from the dye laser at $10 \mathrm{kHz}$ repetition-rate is $0.3 \mathrm{~mJ} /$ pulse and collimated sheet optics are used to obtain a laser sheet with an approximate height of $21 \mathrm{~mm}$. A CMOS sensor camera (Photron FASTCAM SA1.1), an external intensifier (LaVision HS-IRO) with a $100 \mathrm{~mm} \mathrm{f} / 2.8 \mathrm{UV}$ lens (Cerco), coupled with a high transmissivity interference filter (LaVision $1108760 \mathrm{VZ}$ ), are used to collect the $\mathrm{OH}$ signal at $320 \mathrm{~nm}$. The imaging field of view through this setup is $50 \mathrm{~mm} \times 100 \mathrm{~mm}$ and the intensifier gate is $100 \mathrm{~ns}$ to reduce background flame luminosity in the images. The resulting resolution of the OH-PLIF images from this setup is $0.1 \mathrm{~mm} /$ pixel. For each case, 10000 images are acquired.

\section{Image Binarization and Registration}

Raw OH-PLIF images are corrected for laser sheet intensity variations and are filtered using a median and a bilateral filter to reduce noise levels. Dynamic thresholding of filtered images is performed using Otsu's method [49] to obtain instantaneous binary progress variable images and flame edges are obtained by tracing the edges of these binarized images using the ' $b$ wboundaries' function in MATLAB [49]. Time-averaged progress variable fields $(\bar{c})$ are obtained by averaging the binarized images. A non-rigid image is utilized to identify local flame-flame interaction events using MATLAB's 'imregdemons' function. A detailed discussion on the mathematical description of this technique can be found in [36, 37, 50,51]. In this technique, translation operations are performed on consecutive image pairs ('fixed' and 'moved') to account for changes due to local convection and resulting differences are recorded. An example of implementation of this technique to OH-PLIF binarized images is shown in Figure 2. The 'fixed' image corresponds to the binarized image at $t=t_{0}$ and the 'moved' image correspond to the binarized image at $t=t_{0}+\Delta t$ in this figure. The estimated non-rigid displacement fields are operated on the 'moved' image and the difference between the 'registered moved' image and the 'fixed' image correspond to topological differences in these flames within $100 \mu \mathrm{s}$ (shown by arrows in Figure 2). Edges of topologically changing regions are calculated and decomposed into two parts: part of the flame edge that is consumed and the part that remains on the connected flame 
edge after the interaction occurs. For all changes identified, comparisons between the arc-lengths of consumed and remaining flame edges are made to only capture flame surface reduction events. Interactions due to existing flame pockets on attached flame fronts and merging/breaking of flame pockets are not counted in the interaction statistics. Additionally, interactions comprising of regions with 25 pixels or less are excluded in the current analysis to avoid registering non-physical topological changes as flame-flame interactions.
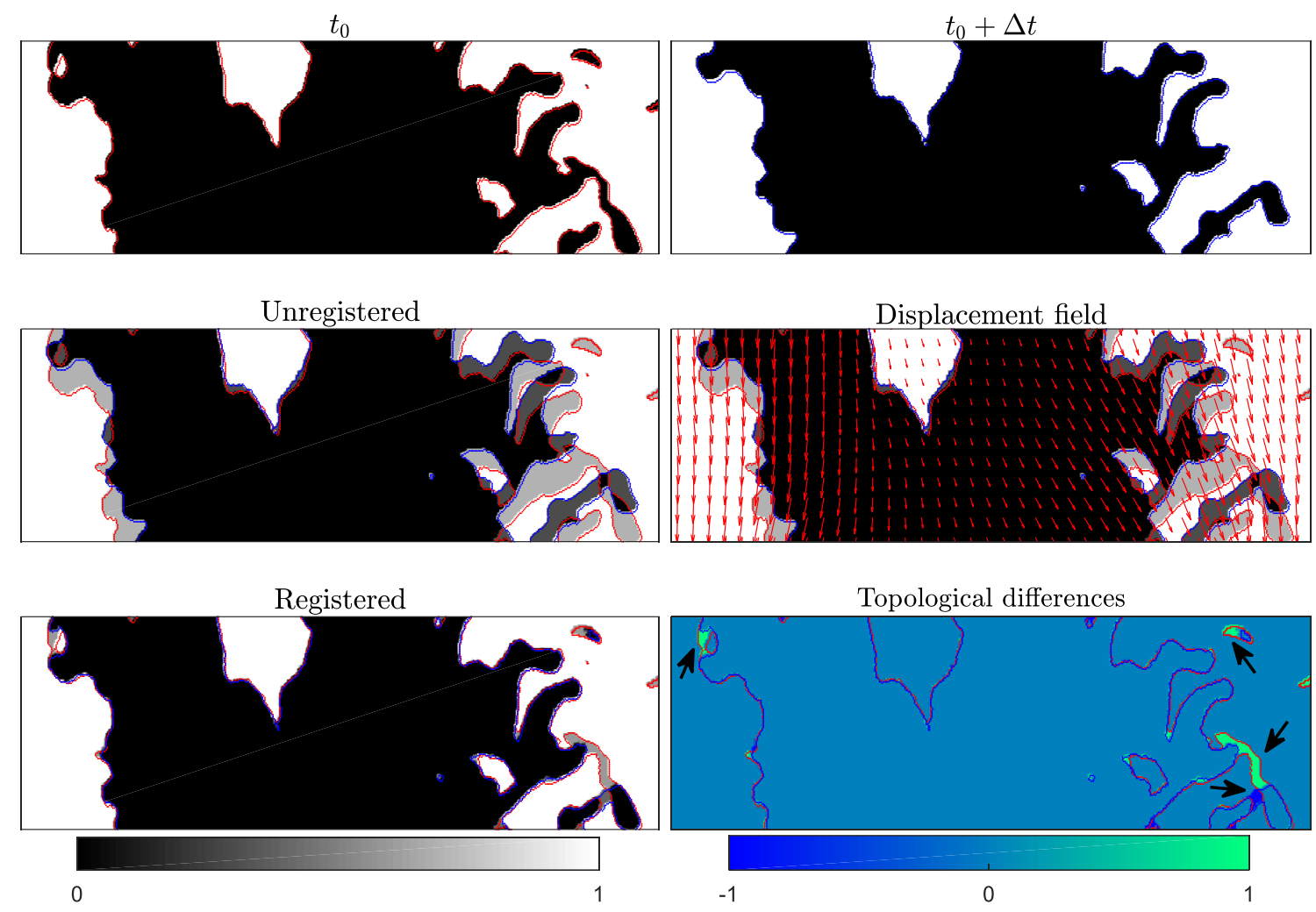

Figure 2: Example of application of non-rigid image registration methodology on binarized OHPLIF images

\section{Results}

\section{A. Test Matrix}

Table 1 shows the operating conditions for V-flames investigated in this study. For these flames, the equivalence ratio $(\phi)$ is kept close to 0.9 and the flame spacing $(S)$ is kept at $55 \mathrm{~mm}$ to ensure stabilization of flames on the bluffbodies in each burner. While the equivalence ratio varies slightly, we do not expect it to significantly alter the flame interaction behavior because the flame speed and stretch sensitivity of the flames in this range are not highly sensitive to small changes in equivalence ratio. The interaction zones for these flames are located in FOV III and IV (Figure 1(b)) and the focus of this study is on characterization of the interacting flame behavior in FOV IV.

Table 1: Operating conditions for flames studied in the paper

\begin{tabular}{cccccccccc} 
Case & $\begin{array}{c}\boldsymbol{U} \\
{[\boldsymbol{m} / \boldsymbol{s}]}\end{array}$ & $\boldsymbol{\phi}$ & $\begin{array}{c}\boldsymbol{u}^{\prime} \\
{[\boldsymbol{m} / \boldsymbol{s}]}\end{array}$ & $\begin{array}{c}\boldsymbol{L}_{\mathbf{1 1}} \\
{[\boldsymbol{m m}]}\end{array}$ & $\boldsymbol{u}^{\prime} / \boldsymbol{s}_{\boldsymbol{L}}$ & $\boldsymbol{L}_{\mathbf{1 1}} / \boldsymbol{l}_{\boldsymbol{f}}$ & $\boldsymbol{R e}_{\boldsymbol{L}_{\mathbf{1 1}}}$ & $\begin{array}{c}\boldsymbol{S} \\
{[\boldsymbol{m m}]}\end{array}$ & FOV \\
\hline Flame A & 13 & 0.90 & 2.3 & & 6.4 & 8.6 & 343 & & \\
Flame B & 18 & 0.93 & 3.2 & 2.2 & 8.9 & 9.2 & 500 & 55 & IV \\
Flame C & 19 & 0.95 & 3.4 & & 9.4 & 9.6 & 555 & & \\
\hline
\end{tabular}




\section{B. Time-Averaged Flame Structure}

Figure 3(a) shows the time-averaged progress variable $(\bar{c})$ fields of flames A - C in FOV IV. Results from this FOV are particularly interesting as the merging of flow fields from both burners can be expected in this region and a large amount of wrinkling is present along the flame fronts. Visually, $\bar{c}$ fields show minor differences in flame development between the left and the right burners. These may exist due to minor geometry differences in the turbulence generation plates between the left and the right burner and it is believed that this difference has negligible effects on the analysis carried out in this study. The $\bar{c}$ fields between flames A - C show little variation between each case, indicating that small variations in turbulence levels do not significantly affect the time-averaged flame structure. To highlight the differences in flame structure in the central region, horizontal slice comparisons of $\bar{c}$ of flames A - C at various downstream locations are shown in Figure 3(b). The $\bar{c}$ profiles for these flames show values greater than zero in this region, indicating that flame fronts along the inner flame branches interact with each other. These inner branches of the left and right flames do not mutually merge with each other in this region; however, strong flame front motions are present in the cross-stream directions along the inner flame branches, indicating that the presence of an adjacent flame results in changes in flame propagation, as highlighted by the $\bar{c}$ contour lines in Figure 3(a). While the outer flame branches have densely packed $\bar{c}$ contours, the inner flame branches show sparse distributions of some of these $\bar{c}$ contours. Additionally, $\bar{c}=0.1-0.3$ contours for the inner branches of left flames are found to be connected to those of the inner branches of the right flames. This indicates that the inner flame fronts can be frequently found near the centerline of the experiment. For this study, we call this central region as the interaction zones of these flames.
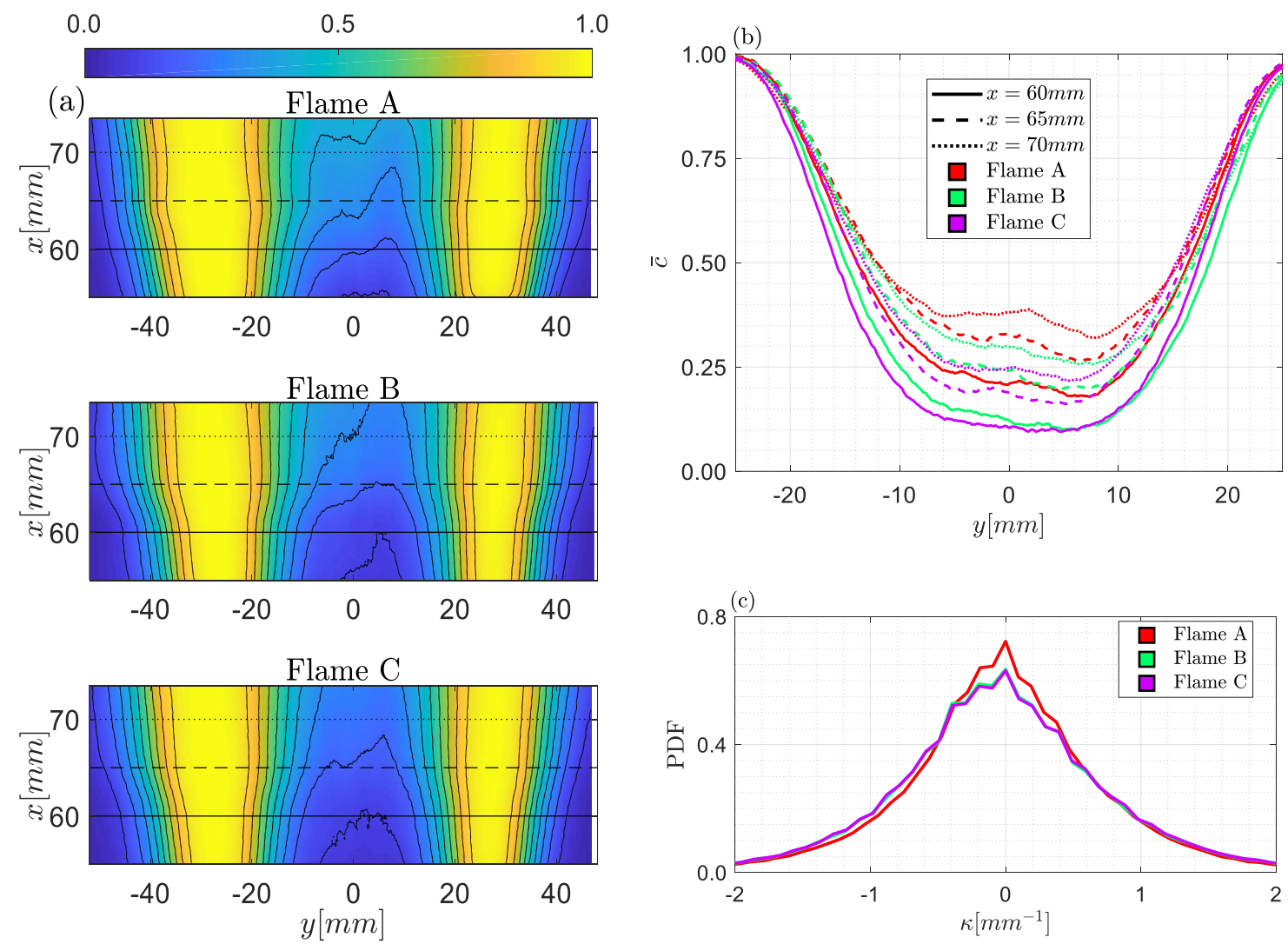

Figure 3: (a) Time-averaged progress variable fields $(\bar{c})$ for flames A - C in FOV IV, (b) horizontal slice comparisons of $\bar{c}$ at $x=60 \mathrm{~mm}, 65 \mathrm{~mm}$, and $75 \mathrm{~mm}$, and (c) PDFs of total flame curvatures ( $\kappa$ )

Comparisons between the inner and outer flame branches for all cases show that differences in spatial distributions exist for $\bar{c}=0.1-0.5$. Larger differences exist between adjacent $\bar{c}$ contours in this range in the inner flame branches compared with the outer flame branches. For example, the spatial variation between $\bar{c}=0.1$ and $\bar{c}=0.5$ in the inner branch of the left flame for flame $\mathrm{C}$ is as large as $18.4 \mathrm{~mm}$, while the same $\bar{c}$ spatial variation in the right branch is 7.7 $\mathrm{mm}$, showing that the inner flame front spatial variation is at least two times as large as the outer flame front. These differences suggest that large-scale fluctuations along the flame front in the cross-stream direction are present in the 
inner flame branches that may exist due to interactions between the two flames. For flame A, $\bar{c}$ values vary from 0.2 -0.4 vertically along $x=60 \mathrm{~mm}-70 \mathrm{~mm}$. However, for flames B and C, $\bar{c}$ values vary from $0.1-0.3$ and $0.10-0.25$, respectively. Less variation in $\bar{c}$ values for flames with higher bulk flow velocities shows that increasing Reynolds number results in a lower probability of finding the flame front in the interaction zone. These differences suggest that interacting flames affect the distribution of the flame brush in the interaction zone and while the interaction only affects a small range of the flame brush $(\bar{c}=0.1-0.5)$, it can also affect the dynamics of the flame structure in this region. As noted previously, the local flame structure directly correlates with the local turbulent burning velocity and in the next few sections, the behavior of the local flame structure is characterized by presenting statistics of the local flame-flame interaction dynamics of these flames.

\section{Local Flame-Flame Interaction Statistics}

Flame-flame interactions can occur in two ways: normal or counter-normal. For this study, normal interactions are called 'reactant-side interactions' and counter-normal interactions are called 'product-side interactions.' Examples of these interactions for flame $\mathrm{C}$ are shown in Figure 4, where instances of reactant-side interactions are shown by blue arrows and instances of product-side interactions are shown in green arrows. Both types of interactions can result in annihilation of flame surface and formation of flame pockets. In reactant-side interactions, the flame surface can either fold on itself and create a pocket of reactants that is consumed, or mutual interaction can occur between two sections of the flame, resulting in destruction of the flame surface. Like reactant-side interactions, product-side interactions can also either result in pure annihilation of the flame surface or form flame pockets of combustion products. Figure 3(c) shows the PDFs of total flame curvatures of these flames in FOV IV. These curvature PDFs show that a large amount of wrinkling is present along the flame front, suggesting that frequent flame folding and pinch-off events that lead to flame-flame interactions can occur in this FOV, affecting the local turbulent burning velocity of the flames. These flame-flame interaction events are typically three-dimensional and using by twodimensional imaging, only the in-plane component of these events can be identified and reported in this study.
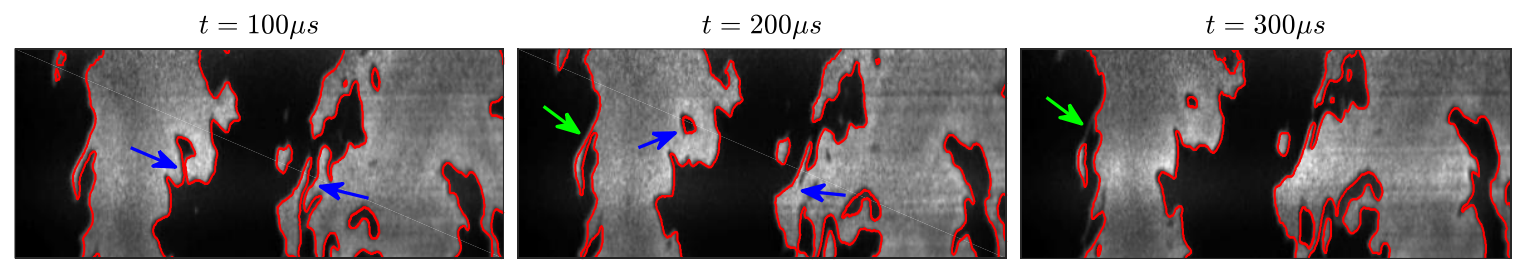

Figure 4: Reactant-side and product-side flame-flame interactions for Flame C

Using the image registration methodology described in section III-C, statistical quantification of reactant- and product-side interactions is performed. Figure 5(a) shows the rates of reactant- and product-side interactions $\left(\mathcal{R}_{\text {Int }}\right.$ ) in Hertz for flames A - C for a period of one second. Since the merging of an existing flame pocket with a flame front is not counted as an interaction in this technique, these rates only include interaction events that occur due to pinch-off or folding of the attached flame front. These results show that more flame-flame interactions events occur as the turbulence levels are increased. Increasing the turbulence levels increases the range of scales of wrinkling on the flame and leads to interactions occurring at a wider range of scales. This observation is true for both reactant-side and product-side interaction events. However, a direct comparison between the two types of interaction rates shows that reactant-side interactions occur almost twice as often as product-side interactions in all flames. In the case of reactantside interactions, the flame fronts propagate towards each other locally while consuming the reactants, showing that flame dynamics are dominant by such events. For product-side interactions to occur, the local flow needs to be highly strained to counter flame propagation in order to cause the flame fronts to fold and merge on the product-side. The vast differences in the reactant- and product-side interaction rates suggest that flame propagation is dominant over the flow strain effects for a majority of the flame-flame interaction events in these flames.

Due to the amount of wrinkling present in flames in this FOV, a large number of flame pockets appear in the $\mathrm{OH}$ PLIF plane of measurement. These flame pockets are generally formed from flame-flame interactions; however, flame pockets can appear from out-of-plane motion or by convecting into the image from the bottom of the frame. Flame pockets can either contain reactant or product gases and depending on the type of the pocket, their dynamics can be quite different. To capture their dynamic nature, a detailed tracking algorithm is implemented. A brief description of this algorithm is presented here: flame pockets in consecutive images are grouped and a convective distance threshold based on $U$ and $u^{\prime}$ is used to predict the location of a pocket of interest in the consecutive frames. Once the location of the pocket in the consecutive frames is identified, an individual label is assigned to the pocket in each frame. These 
steps are followed until further tracking of the pocket is not possible. Figure 5(b) shows the rates of pockets $\left(\mathcal{R}_{p}\right)$ tracked in FOV IV for flame A - C for a period of one second. Results presented here show that similar magnitudes of pocket rates are obtained for both reactant and product pockets for all flames. As noted previously, increasing turbulence levels increases the amount of wrinkling and the range of length-scales present in the flow, resulting in the increased pocket formation.
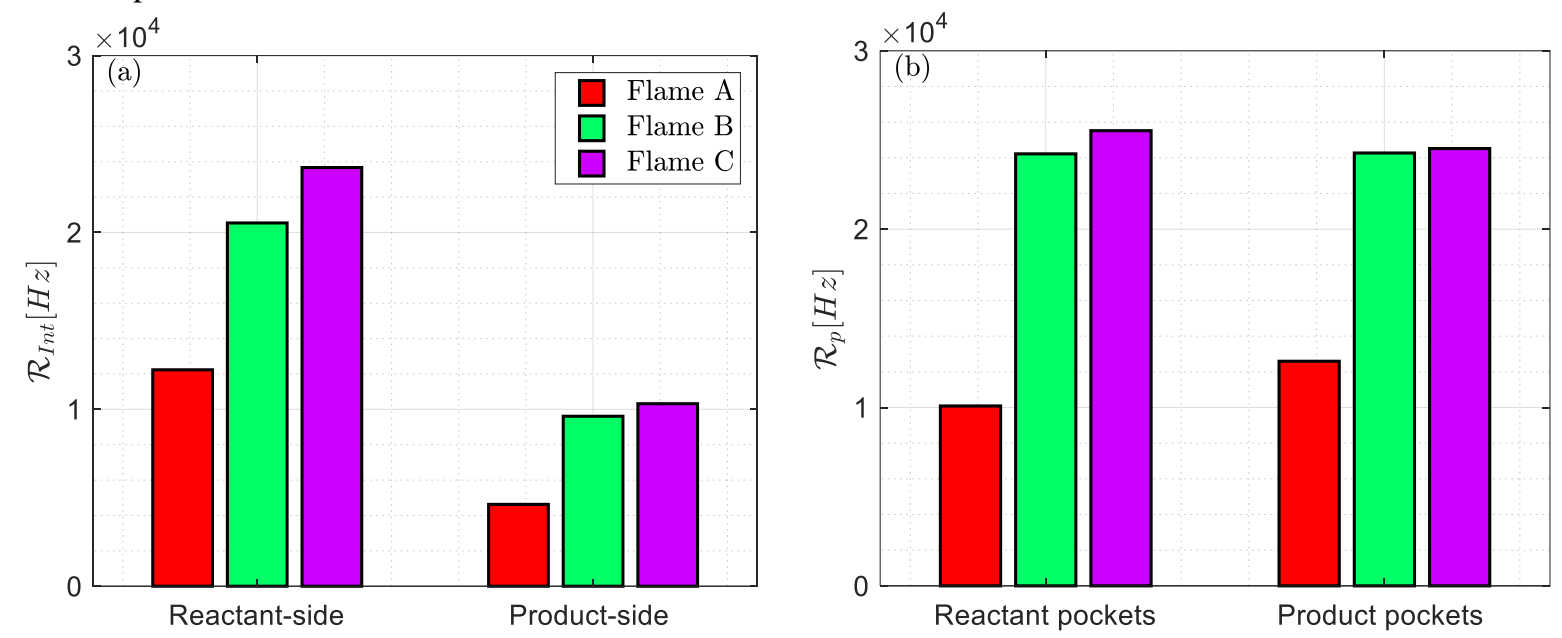

Figure 5: (a) Reactant- and product-side interaction rates $\left(\mathcal{R}_{I n t}[\mathrm{~Hz}]\right)$, and (b) rates of pocket formations $\left(\mathcal{R}_{p}[\mathrm{~Hz}]\right)$ in flames A - C

A comparison between interaction rates and pocket rates shows that a similar number of reactant-side interactions and flame pockets occur for flames A - C in FOV IV, indicating that most reactant-side interactions form pockets. However, the product pocket rates obtained are almost twice as large as the product-side interaction rates for these flames. This anomaly suggests that more product pockets are observed in the plane of measurement compared to the product-side interaction events, which could be attributed to the out-of-plane motions present in this FOV.

To understand the discrepancy in the product-side interaction rates and product pocket rates, the pocket tracking algorithm and image registration technique are used to quantify the 'origin' and 'fate' of individual pockets. The tracking stores the instances of a pocket's initial and final spatial locations and lifetime. This information, coupled with image registration, allows us to check whether the pocket originates from a flame-flame interaction event or through other mechanisms. Three categories of the origin of each pocket are identified: 1) if a pocket appears into the FOV due to convection, it is categorized under 'From bottom'; 2) if the pocket appears from out-of-plane, it is categorized under 'Appear; 3 ) if the pocket is formed due to an observed flame-flame interaction, it is categorized under 'Interaction'. Similarly, the fate of the pocket is identified and grouped into three categories: 1) if the pocket convects out of the FOV, it is categorized under 'Moved out'; 2) if the pocket disappears or burns out, it is categorized under 'Disappeared/Consumed'; 3 ) if the pocket merges into an existing flame front, it is categorized as 'Merged'. Inspection of the OH-PLIF images suggests that reactant pockets generally burn out and product pockets disappear. These broad categories of the origin and fate of reactant and product pockets not only help with the statistical quantification of their behavior, but also assist in understanding the level of three-dimensionality of flames in this FOV. As a large number of pockets may appear from out-of-plane motions, this categorization of the pockets can help understand the contribution of in-plane vs. out-of-plane flame-flame interaction events on changing the local topology of the measured in-plane flame surface.

Results from this analysis are presented in Figure 6; it is important to note that results shown here only pertain to tracked pockets with information on both the origin and fate. These results show that the observed reactant pockets generally are formed from reactant-side interactions and are consumed in the same plane of measurement. While some of these pockets appear from out-of-plane or are convected into this plane, they contribute to a smaller proportion of the tracked pockets. Results on the fate of reactant pockets show that a majority of the pockets are consumed in the same plane of measurement and small proportions of these pockets convect out of the frame or merge with existing flame fronts. The results on the product pockets are interesting as they show that most of these pockets appear from out-of-plane motions and small proportions of these pockets originate from product-side interactions and bulk convection. These differences explain the differences between the product-side interaction and pocket rates reported in Figure 5. These results also suggest that pockets formed from out-of-plane product-side interaction events contribute to a large proportion of the pockets observed in the current plane of measurement. The fate results of the product 
pockets show that a majority of the pockets disappear; however, a significant proportion of the pockets merge into attached flame fronts. Merging of product pockets, as well as reactant pockets, into existing flame fronts results in addition of flame surface, consequently changing the local burning intensity of the reactant gases.
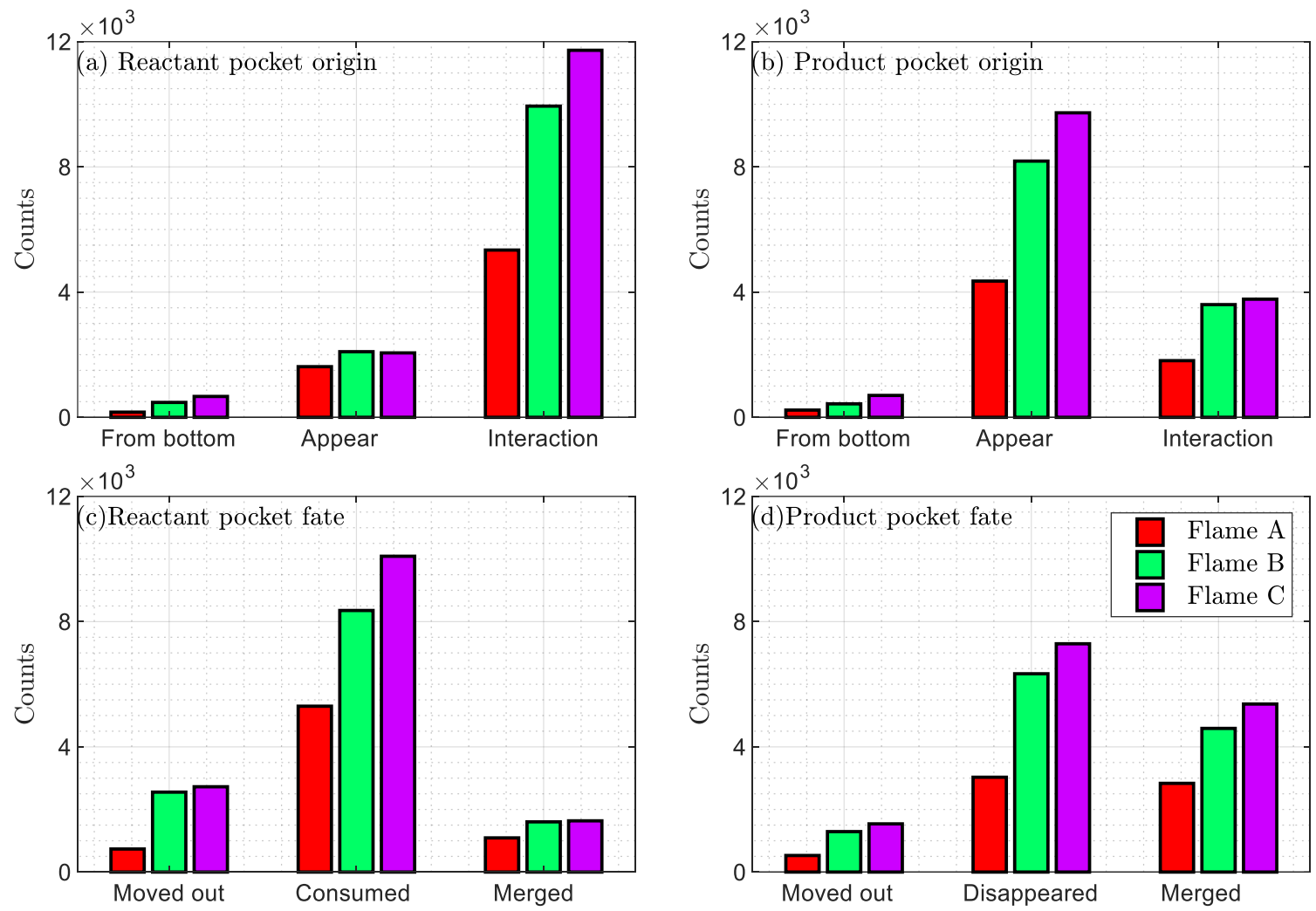

Figure 6: Origin of (a) reactant pockets and (b) product pockets. Fate of (c) reactant pockets and (d) product pockets

Figure 7 shows the PDFs of $\bar{c}$ at the locations of reactant- and product-side interaction events. The PDF plots for product-side interactions show peaks around $\bar{c}=0.1-0.3$, suggesting that product-side interactions mostly occur along the reactant side of the flame brush. On the other hand, the PDF plots for reactant-side interactions for flames A - C show that these interaction events are distributed over a wide range of $\bar{c}$ values. Inspection of OH-PLIF images shows that the width of the flame brush in this region is a result of large-scale flame motions, and that interactions occur at smaller length-scales on top of these large-scale motions. As such, the distribution of interactions is spread across a wide range in progress variable space. In the next section, these large-scale motions are identified and their effect on flame-flame interaction events are considered.
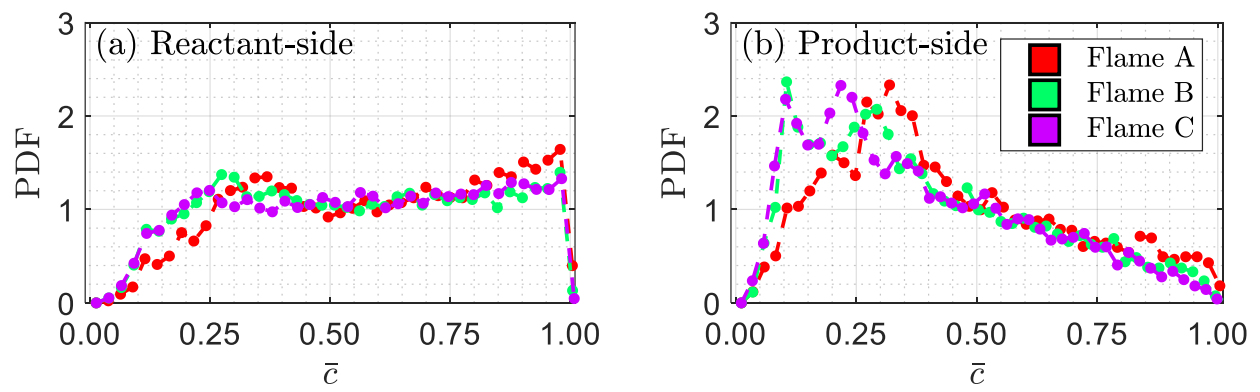

Figure 7: PDFs of $\bar{c}$ at flame-flame interaction locations for (a) reactant-side and (b) product-side flameflame interactions 


\section{Impact of Large-Scale Motions on Local Flame-Flame Interactions}

To identify coherent motions in the flames, the $\bar{c}$ fields are subtracted from the instantaneous binarized images $\left(I_{b}\right)$ to obtain time-varying fluctuating images $\left(I^{\prime}\right)$ for flames A - C, as described in Equation (1).

$$
I^{\prime}(t)=I_{b}(t)-\bar{c}
$$

Using this Reynolds decomposition, a time-series of fluctuating intensity values for each pixel is obtained. A fastFourier transform of $I^{\prime}$ is performed to obtain the frequency spectrum of the flame fluctuation at every location. For this study, this Fourier analysis is performed at three probe locations in different regions of $\bar{c}$ fields, as shown by black dots in Figure 8. These locations are specifically chosen to capture large-scale motions along the inner branches of the left and right flames, as well as along the central part of the interaction zone.

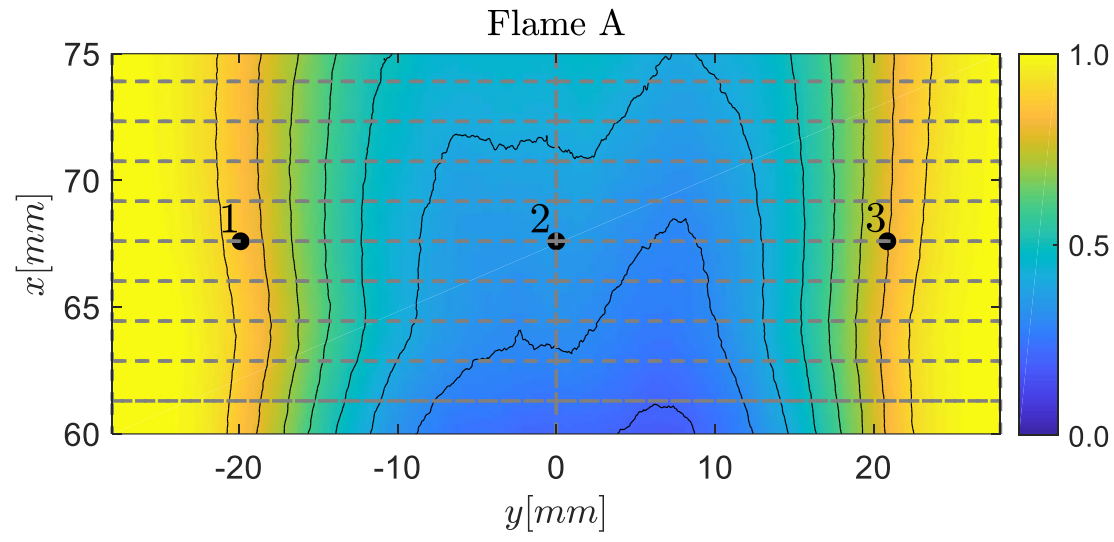

Figure 8: Probe locations for spectral analysis of flame front in inner flame branches and the interaction zone (black dots). Dashed gray boxes represent bins in vertical direction along the inner flame branches for the left and the right flames

Power spectral densities (PSDs) of $I^{\prime}$ for flames A - C at probe locations 1, 2, and, 3 are shown in Figure 9 (a), (b), and, (c), respectively. These results show strong oscillations in the inner flame branches at frequencies of $105 \mathrm{~Hz}, 140$ $\mathrm{Hz}$, and, $150 \mathrm{~Hz}$ for flames $\mathrm{A}, \mathrm{B}$, and, C, respectively. The interaction zone oscillations correspond to the first harmonic of the peak frequencies observed along the inner flame branches. Additionally, as the bulk flow velocity is increased, these peak frequencies also increase. Bénard von Kármán vortex shedding observed in bluff-body flows corresponds to a Strouhal number $(S t)$ in the range of $0.2-0.3$ [52] and for the peak frequencies identified here, the range of $S t$ is $0.026-0.052$. This $S t$ range indicates that the strong oscillations that the flames undergo do not originate from vortex shedding behind a circular bluff-body and suggest that other coherent motions are present in the inner flame branches and the interaction zones.
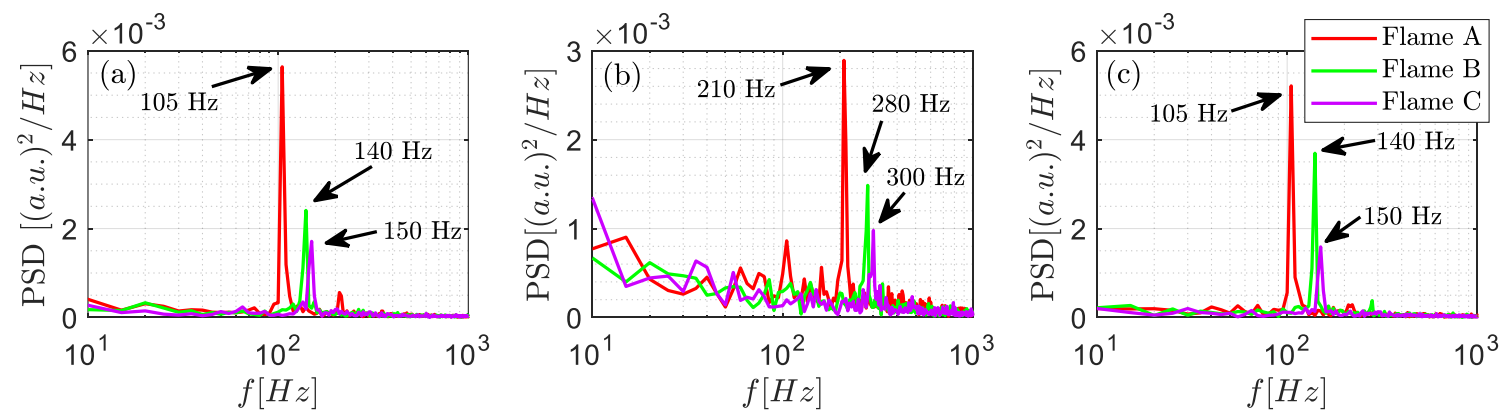

Figure 9: Power spectral densities of flame front fluctuations in (a) left flame inner branch, (b) interaction zone, and (c) right flame inner branch

To further investigate the nature of these oscillations, harmonic reconstruction of $I^{\prime}$ is performed to isolate motions corresponding to each peak frequency obtained from the Fourier analysis. This reconstruction is obtained by first 
calculating the amplitudes $(\mathcal{A})$ and phase angles $(\theta)$ of the fast-Fourier transform of $I^{\prime}(t)$, obtained from the expression shown in Equation (2):

$$
\hat{I}(f)=\mathcal{A} \exp (-i \theta)
$$

The harmonic reconstruction at a frequency of interest is calculated using Equation (3):

$$
\tilde{I}_{\left.\right|_{f=f_{0}}}(t)=\mathfrak{R}\{\mathcal{A}(f) \exp (-i \theta(f)) \exp (-2 \pi i f t)\}
$$

Here, $\Re$ corresponds to the real-part of the expression. The image reconstruction is done over a limited region of the full image, shown in Figure 8. To increase the computational speed for reconstructions, images are down-sampled by a factor of 16 and $\hat{I}(f)$ and $\tilde{I}(t)$ are obtained at each "super-pixel" location. This down-sampling results in a resolution of $1.6 \mathrm{~mm} /$ pixel. Figure 10 shows one cycle of harmonically reconstructed oscillations at frequencies of $105 \mathrm{~Hz}$ and $210 \mathrm{~Hz}$ for flame A. These images show convective oscillations that span greater than half of the height of the FOV. Specifically, in the case of $105 \mathrm{~Hz}$ (Figure 10 (a)), complete out-of-phase oscillations occur in the inner branches for both flames. These oscillations are not present in the outer flame branches of these flames (not shown), which indicates that the interaction between these flames strongly affects the flame branches in the interaction zones. Similar to flame A, these convective out-of-phase oscillations are also present in flames B and C at peak frequencies of $140 \mathrm{~Hz}$ and $150 \mathrm{~Hz}$, respectively.

Flame-flame interaction events can be conditioned on the inner flame branches to directly investigate the effect of large-scale motions of the flame branches. This is achieved by creating interrogation windows along the $x$-direction for each flame branch and assigning whether the interaction occurs along the inner branch of the left or the right flame. The size of the interrogation windows is set at 16 pixels in the vertical dimension, resulting in a resolution of $1.6 \mathrm{~mm}$. These interrogation windows are shown in gray dashed-lines in Figure 8. Since flame-flame interactions can occur over a wide range of scales, the centroids of the shapes of the interactions are used to obtain a single mean location in the $x$-direction. These centroid locations are used to populate the interrogation windows and the spatial variation of flame-flame interaction events are obtained; these results are presented in Figure 11(a) and (b). For all flames, reactantand product-side interactions are counted separately along the inner flame branches. Results for the reactant-side interactions show that in the current FOV, counts of interaction events tend to increase in the range of $x=55 \mathrm{~mm}-62$ $\mathrm{mm}$ and then decrease from $x=63 \mathrm{~mm}-72 \mathrm{~mm}$. The trends between the left and the right flame branches are similar to each other and for all flames shown here. For product-side interactions, differences exist between flame A and flames B and C; interaction counts for flame A show a peak near $x=64 \mathrm{~mm}$, while two peaks occur near $x=57 \mathrm{~mm}$ and $67 \mathrm{~mm}$ for flames $\mathrm{B}$ and $\mathrm{C}$. These results along the inner flame branches suggest that for reactant-side interactions, an increase in inlet Reynolds number only affects the intensity of these interactions and not their spatial distributions, On the other hand, for product-side interactions, the intensity, as well as the spatial distribution, are changed due to the increase in inlet Reynolds number.

To link the large- and small-scale motions, time series of the interaction event counts are extracted for each interrogation window along the inner flame branches; an example of such a time-series is shown in Figure 11(c). While the interactions may seem intermittent, there is a connection between the time-scales of interactions and the large-scale frequencies shown in Figure 9. Arrival frequencies of interaction events are calculated by evaluating the time delay between the occurrence of consecutive interaction events $\left(\Delta t_{i n t}\right)$ in an interrogation window location. These time-scales are inverted to obtain an arrival frequency $\left(f_{a}\right)$, as shown in Equation (4):

$$
f_{a}=1 / \Delta t_{\text {int }}
$$

This analysis is performed at all interrogation window locations and for reactant- and product-side interaction events. Histogram maps of arrival frequencies as a function of downstream location are shown in Figure 12. The left column in this figure correspond to reactant-side interactions and the right column corresponds to product-side interactions. The histogram maps show that reactant-side interaction events occur for a wide range of $f_{a}$ values in both inner flame branches. It is also interesting to note that near $x=62 \mathrm{~mm}$, the range of $f_{a}$ is broad, indicating a large number of interactions occurring for flames A - C as previously highlighted in Figure 11. The broadband distribution of interaction frequencies is likely driven by turbulent flame wrinkling. Additionally, a high number of lower frequency interactions in the ranges of $100 \mathrm{~Hz}-500 \mathrm{~Hz}$ suggests that the large-scale oscillations corresponding to 105 $\mathrm{Hz}, 140 \mathrm{~Hz}$, and $150 \mathrm{~Hz}$ may drive the occurrence of reactant-side interactions in both flame branches. Similarly, for 
product-side interactions, a majority of $f_{a}$ values fall in the low frequency ranges $(100 \mathrm{~Hz}-500 \mathrm{~Hz})$, suggesting that large-scale flame motions play a role in facilitating interactions.
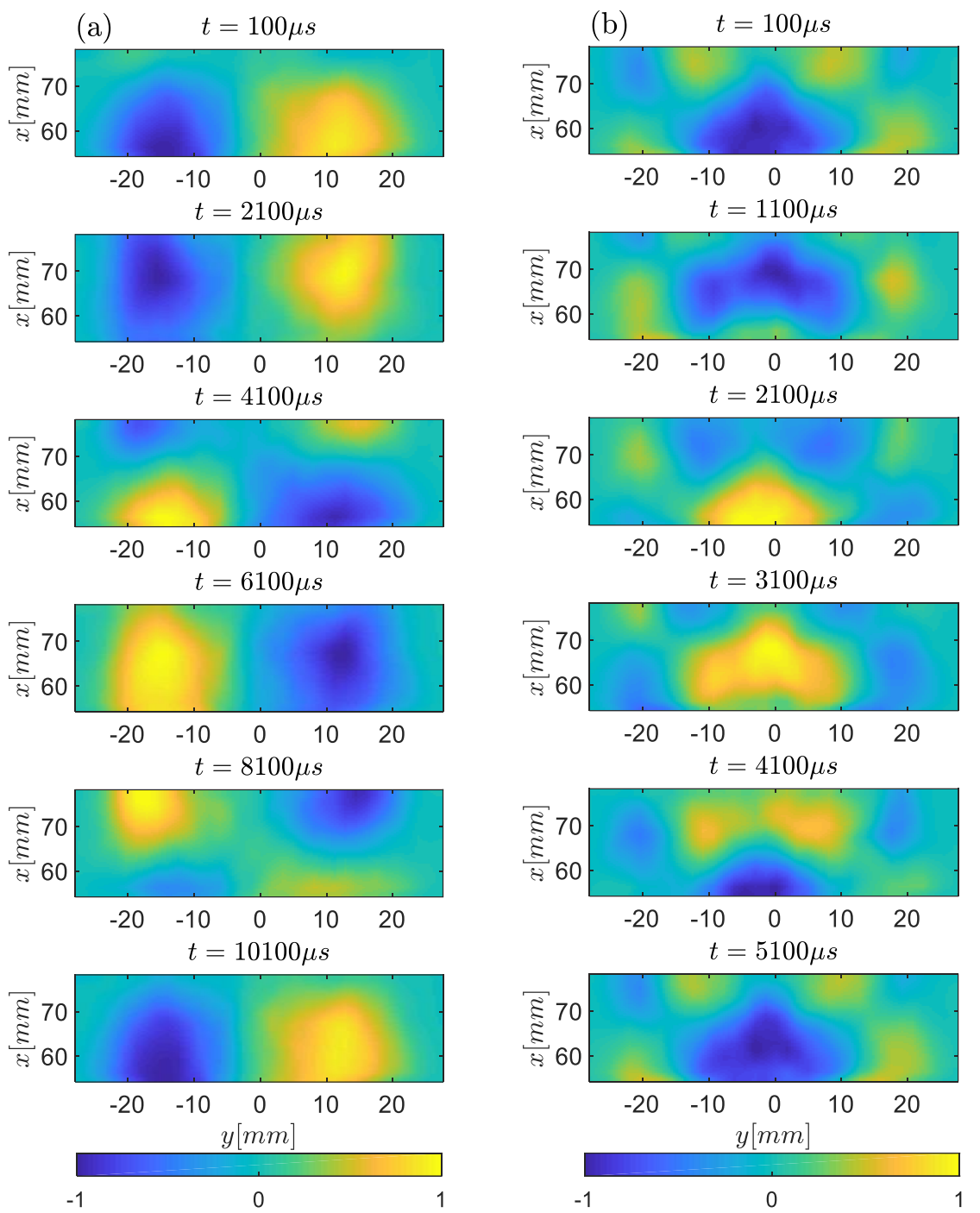

Figure 10: Time-series of harmonically reconstructed large-scale flame motions at (a) $105 \mathrm{~Hz}$ and (b) 210 Hz for flame A

These results suggest that while local turbulence and flame wrinkling can be the primary mechanisms leading to flame-flame interactions, large-scale oscillations are equally important in the occurrence of these interactions. The connection between flame annihilation events and large-scale motions aligns with previous studies on thermoacoustically unstable systems, where large-scale flame oscillations affect the spatial distribution of flame-flame interaction events. Higher arrival frequencies for reactant-side interactions are present in closely packed regions along the $x$-direction, while lower arrival frequencies are present along a wide range of $x$-locations. Similarly, the lower arrival frequencies for product-side interactions are widely distributed along the $x$-direction. This finding connects the large-scale global behavior to the sub-grid level behavior of turbulent flames. 

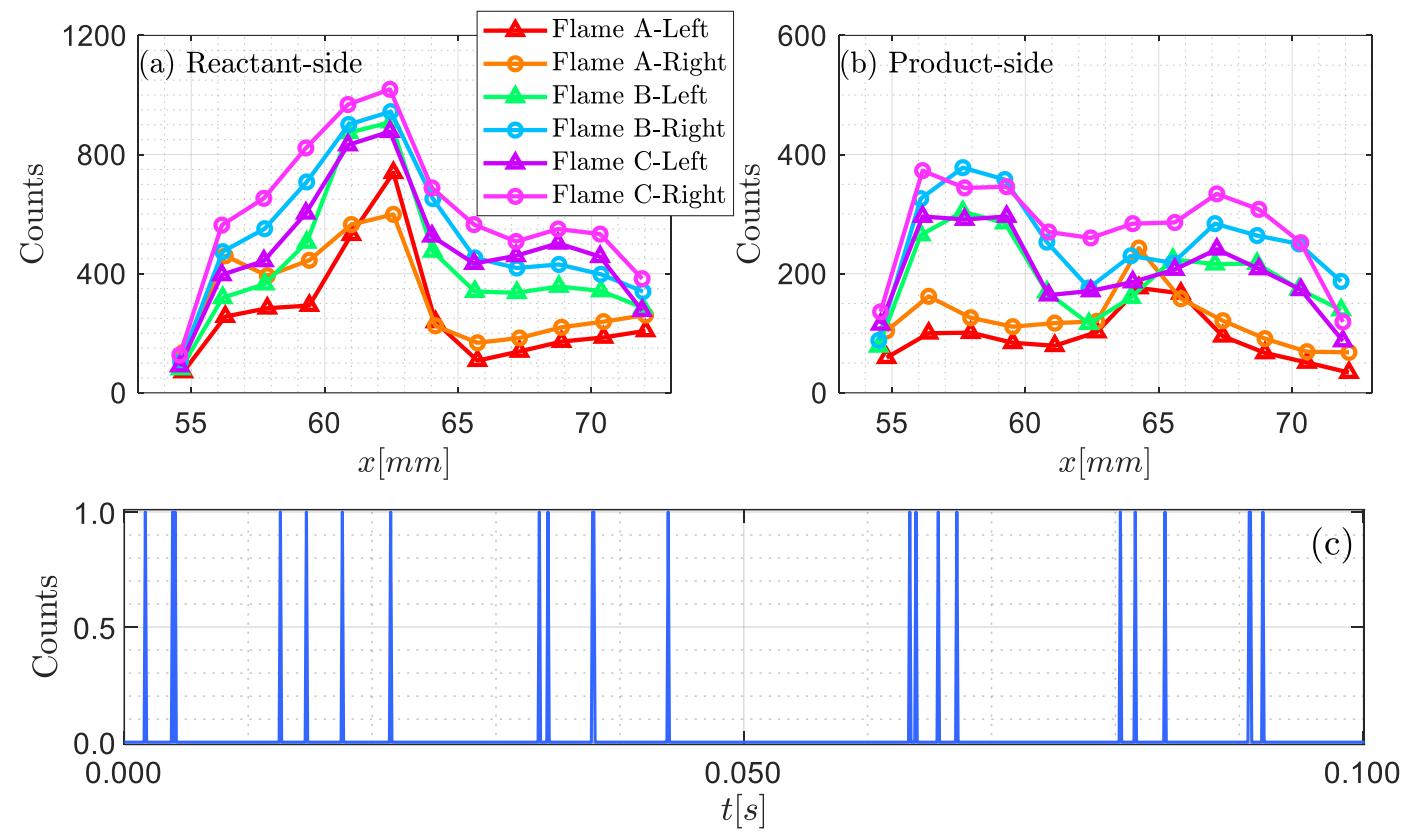

Figure 11: Flame-flame interaction counts for 16-pixel interaction regions along the inner branches of left and right flames: (a) reactant-side and (b) product-side. (c) Example of the time-series of counts of reactant-side interactions at an interrogation window in the inner branch of the left flame

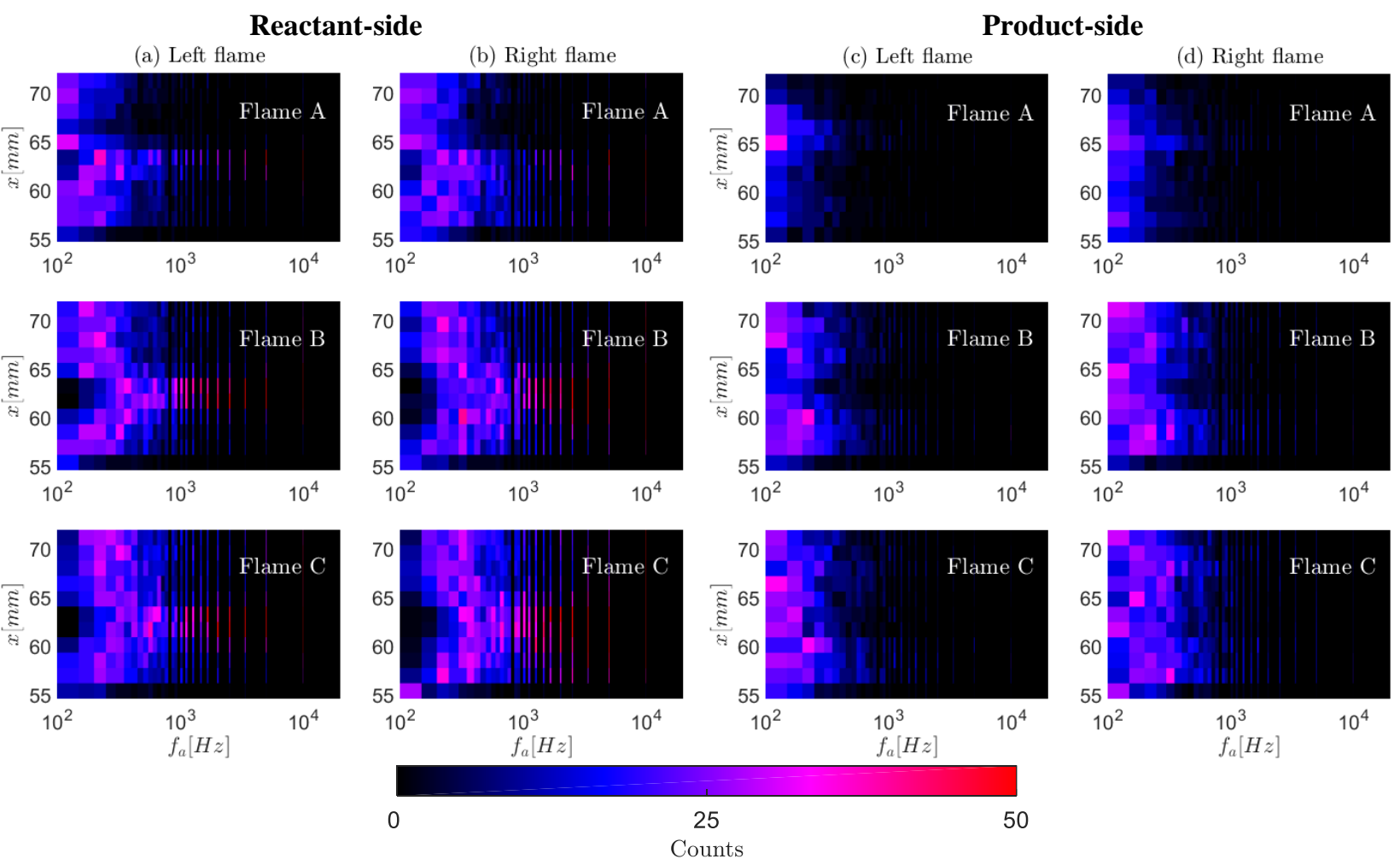

Figure 12: Arrival frequencies for reactant-side flame-flame interactions along the inner branches of: (a) left and (b) right flames. Left column: reactant-side interactions, right column: product-side interactions 


\section{Conclusion}

In this work, a preliminary investigation of the interaction zones of two interacting, turbulent V-flames is performed using high-speed OH-PLIF measurements. The behavior of the local flame structure is characterized by identification of flame-flame interaction events and flame pocket formation using a non-rigid image registration postprocessing technique. Interaction rates and pocket formation rates are found to increase with an increase in turbulence levels. Tracking of lifetime of flame pockets show that a majority of reactant pockets are formed from observed flameflame interactions and end in complete consumption of the reactant gases they contain. On the other hand, a large number of tracked product pockets are shown to appear in the plane of measurement and result in merging with existing flame fronts, changing the local burning velocity of reactant gases. Fourier analysis of the binarized OH-PLIF images shows that low-frequency, large-scale flame oscillations exist in the inner flame branches of these flames. Calculations of the arrival frequencies of flame-flame interactions events show a strong influence of these large-scale, low-frequency oscillations in facilitating the occurrence of the interaction events.

The limited flame/flow configurations in previous DNS studies investigating flame-flame interactions restricts our understanding of local interactions in more realistic configurations and experiments appear to be a viable approach to characterize these effects for a wide range of operating conditions and configurations. Future work from this experiment will include investigation of the interaction zones of V-flames at a wide range of operating conditions, including turbulence length-scales, flame spacing, Reynolds numbers, and, FOVs. Simultaneous particle image velocimetry and OH-PLIF measurements will be performed to support the findings from OH-PLIF images.

\section{Acknowledgments}

This work was supported by the Air Force Office of Scientific Research under Grants FA9550-16-1-0044 and FA9550-16-1-0075 with program manager Dr. Chiping Li. The authors would like to acknowledge Dr. Campbell Carter at the AFRL for providing equipment support for performing these experiments.

\section{References}

[1] Driscoll, J. F. "Turbulent premixed combustion: Flamelet structure and its effect on turbulent burning velocities," Progress in Energy and Combustion Science Vol. 34, No. 1, 2008, pp. 91-134.

[2] Wabel, T. M., Skiba, A. W., and Driscoll, J. F. "Evolution of turbulence through a broadened preheat zone in a premixed piloted Bunsen flame from conditionally-averaged velocity measurements," Combustion and Flame Vol. 188, 2018, pp. 13-27.

[3] Skiba, A. W., Wabel, T. M., Temme, J., and Driscoll, J. F. "Experimental assessment of premixed flames subjected to extreme turbulence," 54th AIAA Aerospace Sciences Meeting, AIAA Paper. Vol. 1454, 2016.

[4] Filatyev, S. A., Driscoll, J. F., Carter, C. D., and Donbar, J. M. "Measured properties of turbulent premixed flames for model assessment, including burning velocities, stretch rates, and surface densities," Combustion and Flame Vol. 141, No. 1-2, 2005, pp. 1-21.

[5] Wabel, T. M., Skiba, A. W., Temme, J. E., and Driscoll, J. F. "Measurements to determine the regimes of premixed flames in extreme turbulence," Proceedings of the Combustion Institute Vol. 36, No. 2, 2017, pp. 1809-1816.

[6] Bell, J. B., Day, M. S., Grcar, J. F., Lijewski, M. J., Driscoll, J. F., and Filatyev, S. A. "Numerical simulation of a laboratory-scale turbulent slot flame," Proceedings of the combustion institute Vol. 31, No. 1, 2007, pp. 1299-1307.

[7] Wabel, T. M., Skiba, A. W., and Driscoll, J. F. "Turbulent burning velocity measurements: Extended to extreme levels of turbulence," Proceedings of the Combustion Institute Vol. 36, No. 2, 2017, pp. 1801-1808.

[8] Kheirkhah, S., and Gülder, Ö. L. "Consumption speed and burning velocity in counter-gradient and gradient diffusion regimes of turbulent premixed combustion," Combustion and Flame Vol. 162, No. 4, 2015, pp. 1422-1439.

[9] Kheirkhah, S., and Gülder, Ö. "Topology and brush thickness of turbulent premixed V-shaped flames," Flow, turbulence and combustion Vol. 93, No. 3, 2014, pp. 439-459.

[10] Kheirkhah, S., and Gülder, Ö. "Turbulent premixed combustion in V-shaped flames: characteristics of flame front," Physics of Fluids Vol. 25, No. 5, 2013, p. 055107.

[11] Steinberg, A. M. "The dynamics of turbulent premixed flames: Mechanisms and models for turbulence-flame interaction." University of Michigan, 2009.

[12] Lipatnikov, A., and Chomiak, J. "Turbulent flame speed and thickness: phenomenology, evaluation, and application in multi-dimensional simulations," Progress in energy and combustion science Vol. 28, No. 1, 2002, pp. 1-74. 
[13] Shepherd, I. "Flame surface density and burning rate in premixed turbulent flames," Symposium (International) on Combustion. Vol. 26, Elsevier, 1996, pp. 373-379.

[14] Pfadler, S., Löffler, M., Dinkelacker, F., and Leipertz, A. "Measurement of the conditioned turbulence and temperature field of a premixed Bunsen burner by planar laser Rayleigh scattering and stereo particle image velocimetry," Experiments in fluids Vol. 39, No. 2, 2005, pp. 375-384.

[15] Zhou, B., Brackmann, C., Li, Q., Wang, Z., Petersson, P., Li, Z., Aldén, M., and Bai, X.-s. "Distributed reactions in highly turbulent premixed methane/air flames: Part I. Flame structure characterization," Combustion and Flame Vol. 162, No. 7, 2015, pp. 2937-2953.

doi: https://doi.org/10.1016/j.combustflame.2014.12.021

[16] Sponfeldner, T., Boxx, I., Beyrau, F., Hardalupas, Y., Meier, W., and Taylor, A. M. "On the alignment of fluid-dynamic principal strain-rates with the 3D flamelet-normal in a premixed turbulent V-flame," Proceedings of the Combustion Institute Vol. 35, No. 2, 2015, pp. 1269-1276.

[17] Prasad, R., and Gore, J. "An evaluation of flame surface density models for turbulent premixed jet flames," Combustion and flame Vol. 116, No. 1-2, 1999, pp. 1-14.

[18] Meneveau, C., and Poinsot, T. "Stretching and quenching of flamelets in premixed turbulent combustion," Combustion and Flame Vol. 86, No. 4, 1991, pp. 311-332.

[19] Duclos, J., Veynante, D., and Poinsot, T. "A comparison of flamelet models for premixed turbulent combustion," Combustion and flame Vol. 95, No. 1-2, 1993, pp. 101-117.

[20] Veynante, D., Duclos, J. M., and Piana, J. "Experimental analysis of flamelet models for premixed turbulent combustion," Symposium (International) on Combustion. Vol. 25, Elsevier, 1994, pp. 1249-1256.

[21] Hawkes, E., and Cant, R. "A flame surface density approach to large-eddy simulation of premixed turbulent combustion," Proceedings of the Combustion Institute Vol. 28, No. 1, 2000, pp. 51-58.

[22] Bray, K. N. C. "Studies of the turbulent burning velocity," Proc. R. Soc. Lond. A Vol. 431, No. 1882, 1990, pp. 315-335.

[23] Candel, S. M., and Poinsot, T. J. "Flame stretch and the balance equation for the flame area," Combustion Science and Technology Vol. 70, No. 1-3, 1990, pp. 1-15.

[24] Skiba, A. W., Wabel, T. M., Carter, C. D., Hammack, S. D., Temme, J. E., Lee, T., and Driscoll, J. F. "Reaction layer visualization: A comparison of two PLIF techniques and advantages of kHz-imaging," Proceedings of the Combustion Institute Vol. 36, No. 3, 2017, pp. 4593-4601.

[25] Worth, N. A., and Dawson, J. R. "Characterisation of flame surface annihilation events in self excited interacting flames," Combustion and Flame Vol. 199, 2019, pp. 338-351.

[26] Kheirkhah, S., and Gülder, Ö. L. "Influence of edge velocity on flame front position and displacement speed in turbulent premixed combustion," Combustion and Flame Vol. 161, No. 10, 2014, pp. 2614-2626.

[27] Hegde, U., Reuter, D., Daniel, B., and Zinn, B. "Flame driving of longitudinal instabilities in dump type ramjet combustors," Combustion Science and Technology Vol. 55, No. 4-6, 1987, pp. 125-138.

[28] Reuter, D., Hegde, U., and Zinn, B. "Flowfield measurements in an unstable ramjet burner," Journal of Propulsion and Power Vol. 6, No. 6, 1990, pp. 680-685.

[29] Hegde, U., Reuter, D., Zinn, B., and Daniel, B. "Fluid mechanically coupled combustion instabilities in ramjet combustors," 25th AIAA Aerospace Sciences Meeting. 1987, p. 216.

[30] Hegde, U., Reuter, D., and Zinn, B. "Sound generation by ducted flames," AIAA journal Vol. 26, No. 5, 1988, pp. 532-537.

[31] Worth, N. A., and Dawson, J. R. "Cinematographic OH-PLIF measurements of two interacting turbulent premixed flames with and without acoustic forcing," Combustion and Flame Vol. 159, No. 3, 2012, pp. 11091126.

[32] Dawson, J. R., and Worth, N. A. "Flame dynamics and unsteady heat release rate of self-excited azimuthal modes in an annular combustor," Combustion and Flame Vol. 161, No. 10, 2014, pp. 2565-2578.

[33] Worth, N. A., and Dawson, J. R. "Tomographic reconstruction of $\mathrm{OH}^{*}$ chemiluminescence in two interacting turbulent flames," Measurement Science and Technology Vol. 24, No. 2, 2012, p. 024013.

[34] Szedlmayer, M. T., Quay, B. D., Samarasinghe, J., De Rosa, A., Lee, J. G., and Santavicca, D. A. "Forced flame response of a lean premixed multi-nozzle can combustor," ASME 2011 Turbo Expo: Turbine Technical Conference and Exposition. American Society of Mechanical Engineers, 2011, pp. 883-891.

[35] Samarasinghe, J., Peluso, S., Szedlmayer, M., De Rosa, A., Quay, B., and Santavicca, D. "Three-Dimensional Chemiluminescence Imaging of Unforced and Forced Swirl-Stabilized Flames in a Lean Premixed MultiNozzle Can Combustor," Journal of Engineering for Gas Turbines and Power Vol. 135, No. 10, 2013, p. 101503. 
[36] Dunstan, T., Swaminathan, N., Bray, K., and Kingsbury, N. "The effects of non-unity Lewis numbers on turbulent premixed flame interactions in a twin V-flame configuration," Combustion Science and Technology Vol. 185, No. 6, 2013, pp. 874-897.

[37] Dunstan, T., Swaminathan, N., Bray, K., and Kingsbury, N. "Flame interactions in turbulent premixed twin V-flames," Combustion Science and Technology Vol. 185, No. 1, 2013, pp. 134-159.

[38] Chen, C., and Sohrab, S. "Upstream interactions between planar symmetric laminar methane premixed flames," Combustion and flame Vol. 101, No. 3, 1995, pp. 360-370.

[39] Chen, J. H., Echekki, T., and Kollmann, W. "The mechanism of two-dimensional pocket formation in lean premixed methane-air flames with implications to turbulent combustion," Combustion and flame Vol. 116, No. 1, 1999, pp. 15-48.

[40] Echekki, T., Chen, J. H., and Gran, I. "The mechanism of mutual annihilation of stoichiometric premixed methane-air flames," Symposium (International) on Combustion. Vol. 26, Elsevier, 1996, pp. 855-863.

[41] Griffiths, R., Chen, J., Kolla, H., Cant, R., and Kollmann, W. "Three-dimensional topology of turbulent premixed flame interaction," Proceedings of the Combustion Institute Vol. 35, No. 2, 2015, pp. 1341-1348.

[42] Im, H. G., and Chen, J. H. "Preferential diffusion effects on the burning rate of interacting turbulent premixed hydrogen-air flames," Combustion and flame Vol. 131, No. 3, 2002, pp. 246-258.

[43] Kollmann, W., and Chen, J. H. "Pocket formation and the flame surface density equation," Symposium (International) on Combustion. Vol. 27, Elsevier, 1998, pp. 927-934.

[44] Trivedi, S., Griffiths, R., Kolla, H., Chen, J., and Cant, R. "Topology of pocket formation in turbulent premixed flames," Proceedings of the Combustion Institute, 2018.

[45] Ranganath, B., and Echekki, T. "Effects of preferential and differential diffusion on the mutual annihilation of two premixed hydrogen-air flames," Combustion Theory and Modelling Vol. 9, No. 4, 2005, pp. 659-672.

[46] Ranganath, B., and Echekki, T. "On the role of heat and mass transport during the mutual annihilation of two premixed propane-air flames," International journal of heat and mass transfer Vol. 49, No. 25, 2006, pp. 5075-5080.

[47] Sun, C., and Law, C. "On the consumption of fuel pockets via inwardly propagating flames," Symposium (International) on Combustion. Vol. 27, Elsevier, 1998, pp. 963-970.

[48] Tyagi, A., Boxx, I. G., Peluso, S. J., Shupp, R., and O'Connor, J. "Structure of Flames in Flame Interaction Zones," 2018 AIAA Aerospace Sciences Meeting. 2018, p. 0161.

[49] Gonzalez, R. C., and Woods, R. E. "Digital image processing prentice hall," Upper Saddle River, NJ, 2002.

[50] Vercauteren, T., Pennec, X., Perchant, A., and Ayache, N. "Diffeomorphic demons: Efficient non-parametric image registration," NeuroImage Vol. 45, No. 1, Supplement 1, 2009, pp. S61-S72.

doi: https://doi.org/10.1016/j.neuroimage.2008.10.040

[51] Thirion, J. P. "Image matching as a diffusion process: an analogy with Maxwell's demons," Medical Image Analysis Vol. 2, No. 3, 1998, pp. 243-260. doi: https://doi.org/10.1016/S1361-8415(98)80022-4

[52] Williamson, C. H. "Vortex dynamics in the cylinder wake," Annual review of fluid mechanics Vol. 28, No. 1, 1996, pp. 477-539. 